\title{
Os nós críticos do processo de trabalho na Atenção Primária à Saúde: uma pesquisa-ação
}

\author{
I ${ }^{1}$ Vanessa de Souza Amaral, ${ }^{2}$ Deíse Moura de Oliveira, \\ ${ }^{3}$ Clayver Viktor Moreira de Azevedo, ${ }^{4}$ Rennan Lanna Martins Mafra I
}

Resumo: Pesquisa qualitativa com abordagem da pesquisa-ação cujo objetivo foi identificar os nós críticos inscritos no processo de trabalho da Atenção Primária à Saúde (APS). Participaram 44 profissionais/gestores da APS de um município do interior de Minas Gerais. A coleta de dados ocorreu de junho a dezembro de 2019, por meio da técnica de observação participante e, posteriormente, de oficinas. Os dados foram analisados a partir da técnica de Análise de Conteúdo de Bardin e sob a perspectiva dos referenciais teóricos de Rudimar Baldissera e Paulo Freire. Na análise, emergiram cinco categorias, que expressaram os nós críticos identificados na observação participante e validados pelos profissionais nas oficinas: ambiência, comunicação, educação permanente, planejamento e identidade profissional. Esta pesquisa sinaliza a importância do diálogo e da reflexão crítica das práticas de saúde como instrumentos de transformação do processo de trabalho em saúde.

> Palavras-chave: Atenção Primária à Saúde; equipe interdisciplinar de saúde; trabalho; gestão de mudança; desenvolvimento Institucional.

\author{
${ }^{1}$ Departamento de Medicina \\ e Enfermagem, Universidade \\ Federal de Viçosa. Viçosa-MG, \\ Brasil (vanessa.s.amaral@ufv.br). \\ ORCID: 0000-0002-8435-2868 \\ ${ }^{2}$ Departamento de Medicina e \\ Enfermagem, Universidade Federal \\ de Viçosa. Viçosa-MG, Brasil \\ (dmouradeoliveira@gmail.com). \\ ORCID: 0000-0003-3804-7413 \\ ${ }^{3}$ Departamento de Medicina \\ e Enfermagem, Universidade \\ Federal de Viçosa. Viçosa-MG, \\ Brasil (clayver.viktor@gmail.com) \\ ORCID: 0000-0003-1967-2213 \\ ${ }^{4}$ Departamento de Comunicação, \\ Universidade Federal de Viçosa. \\ Viçosa-MG, Brasil (rennan. \\ mafra@ufv.br). \\ ORCID: 0000-0002-9078-5475
}

Recebido em: 18/07/2020 Aprovado em: 07/12/2020 Revisado em: 20/01/2021 


\section{Introdução}

O Sistema Único de Saúde (SUS) tem como ideário a reestruturação do modelo de atençáo à saúde no Brasil e considera, dentro da organização do cuidado, a Atençáo Primária à Saúde (APS) como porta preferencial de contato dos usuários, sendo reconhecida como o centro de comunicação das Redes de Atenção à Saúde (RAS). No processo de construçáo do SUS, houve a ampliação do acesso aos serviços de saúde, emblematicamente representada pela emergência da Estratégia de Saúde da Família (ESF). Tal ampliação requer, além do aumento da cobertura das açóes e serviços, o enfrentamento aos desafios relacionados ao processo de trabalho e aos modos como os profissionais de saúde agem e desenvolvem suas relaçôes na produção do cuidado em saúde (MENEZES et al., 2020).

No tocante ao processo de trabalho em saúde, seu marco teórico, Ricardo Bruno Mendes-Gonçalves iniciou suas incursôes sobre os estudos neste campo ainda no contexto do Movimento da Reforma Sanitária Brasileira. O autor, fundamentado na teoria marxista, retratou os elementos componentes do processo de trabalho: o objeto (que nem sempre é a saúde, devido ao conjunto de variaçóes que o cerca); o instrumento (podem ser materiais, como equipamentos e insumos e não materiais, como os saberes que se articulam); a finalidade (a intencionalidade do trabalho) e os agentes (sujeito que imprime a ação) (MENDES-GONÇALVES, 1986). Neste sentido, o objeto do processo de trabalho não é meramente biológico, mas uma construção social e política. Assim, as práticas de saúde se desenvolvem de acordo com as demandas sociais, e o instrumento do trabalho em saúde também se transforma no modo de produzir e direcionar conhecimento no cotidiano das organizações (MENDES-GONÇALVES, 2017).

Existe um espaço intercessor que permeia a práxis do trabalho em saúde, em que todos os atores exercem suas subjetividades, seus modos de agir - em meio aos quais se evidenciam as relações hierarquizadas, as responsabilidades e as competências diversas. Essas especificaçôes exercem influências no processo de trabalho e exigem o reconhecimento da negociação, dos conflitos e do encontro com o outro (MERHY, 1997).

Reconhecer e atuar sobre este contexto é desafiador para os trabalhadores da saúde, sendo necessária sua valorização nas práticas e pesquisas que se debruçam no âmbito da micropolítica do trabalho em saúde, no qual se constrói cotidianamente o 
SUS. Entre os desafios enfrentados pelo sistema de saúde no contexto micropolítico da APS, demarca-se a organização do trabalho em saúde, considerado pilar fundamental para fortalecer a qualidade da assistência e o acesso aos serviços (SILVA; MATOS; FRANÇA, 2017).

Verifica-se que o processo de trabalho em saúde é uma pauta discutida no âmbito teórico, porém evidências práticas e detalhadas de como despertar e estimular sua reorganização nos serviços de saúde - incluindo o da APS - são escassas. Isso reitera a importância de investigaçóes que elucidem os nós críticos do processo de trabalho em saúde que atravessam o cotidiano dos serviços.

A ausente ou incipiente problematização do processo de trabalho dificulta que ele se transforme, evidenciando a manutenção de problemas que se arrastam por um longo período em virtude da ausência de condiçóes e/ou de cultura do movimento de educação permanente. (FERREIRA et al., 2019). Este, no entanto, é de suma importância nas práticas de saúde, a fim de suscitar no âmbito da micropolítica o encontro de caminhos para resolver situaçôes-problema e promover reconfiguraçóes do trabalho em saúde.

Diante do exposto, as seguintes questôes nortearam esta pesquisa: quais são os desafios inscritos no processo de trabalho em saúde da APS? Qual a percepção dos profissionais de saúde com relação a estes desafios? Como validar tais desafios junto a estes profissionais? Portanto, o objetivo da presente pesquisa foi identificar e validar junto a profissionais de saúde/gestores os nós críticos inscritos no processo de trabalho da APS de um município do interior de Minas Gerais.

\section{Metodologia}

Este artigo é produto de uma dissertação defendida no Programa de Mestrado Profissional de uma universidade pública do interior de Minas Gerais. O recorte ora apresentado constitui parte dos resultados desta pesquisa.

Trata-se de uma pesquisa qualitativa pautada na abordagem da pesquisa-ação. Nesta abordagem, a pesquisa e a ação devem ser construídas e compartilhadas pelo grupo/realidade estudada, com sujeitos implicados em buscar potencialidades na construção de conhecimento científico e de práxis transformadoras (THIOLLENT, 2011). Esta abordagem metodológica contribui para a reflexão sobre tensões e problemas institucionais vivenciados pelos atores sociais diante do fenômeno 
investigado e aproxima o pesquisador do campo - este que, através de valores como engajamento, sensibilidade e vínculo, também interage com o meio e participa do processo de transformação (MORIN, 2004).

Adotou-se como referencial teórico o pesquisador Rudimar Baldissera, que apresenta uma perspectiva para análise da comunicação organizacional sobre o olhar do paradigma da complexidade. Neste sentido, considera que a comunicação organizacional perpassa sobre a dinamicidade, sendo necessário reconhecer os processos que mantêm a organização distante do equilíbrio, observando o estado permanente de desorganização/(re)organização - tensôes, disputas e perturbaçóes - transpondo a comunicaçáo planejada e organizada das práticas cotidianas (BALDISSERA, 2009a).

Adotou-se também como referencial teórico Paulo Freire, com ancoragem nos pressupostos da autonomia, do protagonismo do indivíduo, da dialogicidade, da participação política, do pensamento crítico, da construção coletiva e da transformação social (FREIRE, 1983; 1987).

A pesquisa aconteceu em um município que possui 4.047 habitantes, numa área territorial de $83.038 \mathrm{~km}^{2}$, com densidade demográfica $48,74 \mathrm{hab} . / \mathrm{km}^{2}$, segundo o último censo (IBGE, 2010). O mesmo possui uma concentração de 2.096 habitantes (51,80\%) localizados na zona urbana e 1.951 habitantes $(48,20 \%)$ localizados da zona rural. Apresenta gestão plena na Atenção Básica, com 100\% de cobertura da Estratégia de Saúde da Família. Uma pesquisa realizada em 2019 pelo Instituto Brasileiro de Geografia e Estatísticas (IBGE) evidenciou que desde 2013 a estrutura territorial brasileira tem 5.568 municípios, em sua maioria caracterizada como de pequeno porte - com população inferior a 20.000 mil habitantes (IBGE, 2019). Este estudo, portanto, poderá auxiliar outras realidades com características parecidas no encontro de estratégias cabíveis à macro e micropolítica da reorganização do processo de trabalho em saúde.

Foram convidados a participar do estudo os 56 profissionais/gestores que atuam na APS do município, sendo excluídos os participantes que se encontravam licenciados para tratamento de saúde, em período de férias ou desviados de função, contabilizando (12 profissionais), culminando em 44 participantes.

Dentre estes, três eram enfermeiras (incluindo a coordenadora da APS do município), nove técnicos de enfermagem, 11 agentes comunitários de saúde, um médico, um odontólogo, dois técnicos em saúde bucal, uma nutricionista, uma 
assistente social, um educador físico, um bioquímico, um farmacêutico, um agente de endemia, três auxiliares de limpeza, seis auxiliares-administrativos (recepcionistas), a coordenadora da vigilância em saúde e o secretário municipal de saúde.

No intuito de preservar o anonimato, os participantes foram codificados por meio de uma sigla representativa da categoria profissional a que pertenciam, a saber: ACE (agente de endemia); ACS (agente comunitário); AL (auxiliar de limpeza); AS (assistente social); ASB (auxiliar de saúde bucal); BIO (bioquímica); CD (cirurgiãodentista); EF (educador físico); ENF (enfermeiro) sendo ENF1 a coordenadora da APS; FARM (farmacêutico); GM (gestor municipal); MED (médico); NUT (nutricionista); REC (auxiliar administrativo - recepção); TENF (técnico de enfermagem); VSAT (coordenadora da vigilância sanitária). Tais siglas foram seguidas por um número arábico, correspondente à ordem em que os participantes foram abordados pelos pesquisadores, sendo tal enumeraçáo realizada de modo particularizado para cada categoria profissional, a saber: ACS1, AC2.... ACS11; AL1...AL3, etc.

O artigo retrata os dados coletados no período de junho a setembro de 2019, por meio da inserção dos pesquisadores no campo da pesquisa, utilizando-se inicialmente da técnica da observação participante para o levantamento dos nós críticos do processo de trabalho e posteriormente de duas oficinas com os participantes, com vistas a apresentar, refletir e validar os nós críticos levantados juntos aos atores sociais inscritos na realidade observada.

A observação participante ocorreu em 21 dias de campo, totalizando 115 horas, sendo possível realizá-la todos os dias da semana e em todos os turnos referentes a estes dias, tendo os pesquisadores acompanhado o processo de trabalho da equipe e também de cada profissional/gestor, considerando seu setor de atuação. Foram observadas diferentes dinâmicas e rotinas do serviço, em horários e períodos alternados, considerando as possibilidades apresentadas pelo campo. A observaçáo focalizou os discursos formais e informais, as relaçóes e os desdobramentos das açôes em curso. Essa aproximação foi fundamental para a clareza, a identificação e a compreensão da organização e da dinâmica do processo de trabalho no cenário estudado.

A sistematização da observação participante foi inspirada pela noção de comunicação organizacional proposta por Baldissera (2009b), pautando assim a organização dos dados a partir das seguintes dimensóes: descrição da observação (caracterização do momento da observação - data, local, sujeitos envolvidos, tempo de observação, características do espaço estrutural observado); perspectiva histórica 
(a história do local, que reflete os sentidos e significados construídos no ambiente observado); ambiente físico (o qual permite compreender a organizaçáo, utilização e otimização de espaços e materiais, a infraestrutura e condiçóes de trabalho); gestão e formação (o desenho conformacional da organizaçáo esboça o perfil de suas açôes); atividades propostas e desenvolvidas (compreende se o perfil das atividades corresponde à demanda observada e emergida); envolvimento humano (o modo como os participantes interagem molda a maneira como se comportam em um ambiente, se estabelecem e desenvolvem suas açôes).

Cabe ressaltar que esta etapa da investigação foi minuciosamente descrita pelos pesquisadores em um diário de campo, no qual foram registradas as observaçóes e percepçôes, assim como os diálogos estabelecidos com os atores sociais envolvidos. Os registros realizados continham descriçóes, falas, reflexóes e impressóes dos pesquisadores que serviram de base para sua ação-reflexão-ação no processo da pesquisa. Para análise desses dados, utilizou-se o método de análise de conteúdo de Bardin (BARDIN, 2016) orientando-se por cinco etapas, com uma adaptação realizada pelos pesquisadores.

A primeira etapa foi a leitura aprofundada e minuciosa do diário de campo, que correspondeu a uma varredura de todo o material sistematizado durante a observação participante, permitindo uma análise crítica dos dados coletados. $\mathrm{Na}$ segunda etapa, deu-se a captação de informaçóes centrais relacionadas ao objeto da investigaçáa, momento no qual foram identificados os nós críticos do processo de trabalho, aqui entendidos como aspectos dorsais apreendidos nas práticas cotidianas observadas que se apresentaram como desafios inscritos na micropolítica do processo de trabalho.

De posse de todos os nós críticos identificados, deu-se a etapa de sintetização dos mesmos, agrupando-os em matrizes de sentido comum (a partir da confluência de diversos nós em um nó dorsal), concebidas como categorias temáticas na presente investigação. Paralelamente, deu-se a construção de infográficos, etapa que possibilitou, de forma visual, compreender as relaçóes e interseçóes entremeadas a cada nó crítico emergido no processo de trabalho em saúde observado. Essa representação gráfica permitiu visualizar com clareza os fios condutores para a emergência dos nós dorsais identificados, culminando na última etapa (interpretação dos dados) amparada na literatura temática e nos pressupostos conceituais de Baldissera (2009a) e Paulo Freire (1983; 1987). 
As oficinas ocorreram após a realização da identificação dos nós críticos, sendo gravadas na íntegra e utilizadas como estratégia de coleta de dados e também espaço para validação de análise dos nós críticos identificados pelos pesquisadores. Esta validação é concebida pelo método da pesquisa-ação como uma possibilidade de dialogar com os participantes da pesquisa, dando-lhes a oportunidade de confrontar a interpretação da realidade experienciada com a observada. Neste sentido, torna-se passível de modificaçôes em função de o participante assumir o papel de pesquisador, passível de interpretar a realidade que vive (THIOLLENT, 2011).

As oficinas ocorreram em dois momentos, com duração de aproximadamente uma hora cada, em horários acordados a partir da disponibilidade dos profissionais/ gestores e em uma sala de reunióes na própria unidade de saúde. Essas foram organizadas por meio da apresentaçáo dialógica dos infográficos aos participantes, que permitiram a experimentação da tríade ação-reflexão-ação de cada nó crítico observado, fomentando um olhar distanciado e crítico dos participantes com relação ao processo de trabalho, com vistas à sua transformação. O conteúdo gravado foi transcrito na íntegra e submetido à análise de conteúdo (BARDIN, 2016), resultando na interpretação do processo de validação dos nós críticos a partir da ótica dos atores sociais que participaram da pesquisa.

O estudo obteve parecer favorável do Comitê de Ética e Pesquisa com Seres Humanos (CEP) da universidade a qual os pesquisadores estão vinculados, inscrito sobre o no. 2.879.646 (CAAE: 96401018.3.0000.5153).

\section{Resultados}

Os participantes deste estudo tinham idade entre 23 e 57 anos, sendo 39 do sexo feminino e cinco do sexo masculino. O tempo de atuação como profissionais de saúde/gestores variou de um a 23 anos. O tempo de atuação na APS variou de nove meses a 28 anos e o tempo de atuação no município variou de nove meses a 23 anos.

A análise dos dados permitiu a emersão de cinco categorias temáticas: ambiência, comunicação, educação permanente, planejamento e identidade, denominadas aqui como nós críticos pela equipe de pesquisa. Cada categoria será apresentada iniciando pelos dados emergidos a partir da observação dos pesquisadores e na sequência pelos discursos dos participantes das oficinas. A opção por esta apresentação é para demarcar a dialogicidade inscrita nesta pesquisa-ação. 


\section{Ambiência}

O nó ambiência foi identificado a partir da compreensão do desenho conformacional da organização, sendo observados elementos ligados ao espaço físico, aos fluxos dos serviços e às condiçóes de trabalho que interferem nas rotinas de atendimentos e na qualidade do acesso ofertado aos usuários. Durante a observação, notou-se que a recepçáo funcionava como a espinha dorsal do serviço, cujo espaço estabelecia relação com os usuários, profissionais e gestão. A porta de entrada era a mesma para serviços do Pronto Atendimento (PA) e ESF, e essa conformação era fator de imprecisão e produção de enganos, tanto para a identidade dos serviços quanto para o usuário, que se via perdido dentro do fluxo de atendimento.

Embora o município tenha uma unidade de saúde com uma boa estrutura física, a organização dos serviços, a cada dia de observação, ressaltava como algo necessário a ser repensado. Havia profissional sem local para atendimentos, enquanto salas estavam vazias. Em outros momentos da observação, pode-se notar que os profissionais/gestores demandavam um tempo considerável de deslocamento entre um andar e outro para, por exemplo, pegar um prontuário que ficava na recepçáo.

Como principais desafios relacionados a este nó crítico, destacam-se: o fluxo de serviço fragmentado; o acesso desordenado; a existência de informaçóes sem direcionamento para profissionais e usuários; e a falta de privacidade para os atendimentos devido à configuração estrutural dos espaços. A ambiência é vista, entâo, como um desafio inscrito no processo de trabalho, sendo este identificado na organização do espaço físico, conforme expressam os relatos dos profissionais:

Lá embaixo, no outro andar, eu tenho que pegar as coisas aqui, descer com as coisas, depois subir com as coisas após o atendimento... se esquecer um negócio, tem que voltar e pegar primeiro [...]. (ENF2)

Temos para melhorar: melhorar a ambiência com a definição do espaço para PSF, para ficar mais esclarecido na cabeça do usuário como o PSF funciona. (ENF3)

A ambiência também é retratada nas falas dos participantes como algo que impacta diretamente nos fluxos, na comunicação e na assistência adequada aos usuários que buscam a APS do município:

[...] eu acho que uma coisa vai levando a solução da outra. Por exemplo: quando a gente organizar a ambiência, vai organizar o processo de trabalho, o fluxo, vai melhorar a comunicação, as pessoas vão saber informar melhor[...]. São várias coisas a se fazer, mas fazendo uma já vai melhorando todas. (ENF3) 


\begin{abstract}
Para nós, técnicos, dividir a recepção é bom. Não por questão de trabalho, mas sim a assistência, porque a gente consegue dar mais assistência a quem realmente precisa [...] vê o que tem necessidade e é urgência, o que é consulta de PSF. (TENF1)

Ter outra recepção, não vai ficar aquele acúmulo de gente querendo informação e a recepcionista não tem todas as informaçóes que precisaria para resolver o problema naquele momento. (TENF1)
\end{abstract}

\title{
Comunicação
}

O nó "comunicação" é aqui compreendido como o modo de interação entre sujeitos participantes, ambiente e usuários e a maneira como isso molda o processo de trabalho em saúde. Os elementos de observaçáo referentes à comunicação foram as relaçóes formais e informais estabelecidas, as abordagens nos diferentes contextos, as atividades náo planejadas, o tempo livre entre as atividades, as relaçóes de hierarquização e os conflitos interprofissionais no mundo do trabalho.

A observação participante permitiu a compreensão da dinamicidade e do quantitativo de atividades que acontecem interligadas em um fluxo contínuo e acelerado. $\mathrm{O}$ fluxo de comunicação dentro de cada categoria profissional não se mostrava bem delimitado e direcionado. Por exemplo, muitas funçóes que não eram de competência das enfermeiras chegavam até elas por estarem em posições de liderança, gerando sobrecarga de tarefas e responsabilidades. Além disso, foi observado que alguns participantes não possuíam clareza de como lidar com as demandas que lhe cabiam, ou a quem acessar para que essas demandas fossem solucionadas. A incompreensão dos fluxos e das competências individuais e coletivas configurava como um processo de trabalho conflituoso, com ruídos e pouco resolutivo. Em relação à comunicaçáo do serviço com o usuário, a troca de informaçóes necessitava acontecer de forma mais clara. Observou-se também, no âmbito da comunicaçáo, o pouco uso de tecnologias leves (relacionais), promotoras do vínculo e âncoras para a resolução de muitas demandas emergidas na APS.

Como principais desafios relacionados a este nó crítico, destacam-se: a atuação multiprofissional fragmentada; a fragilidade nos diálogos entre a tríade usuários / profissionais / gestão; o uso incipiente de tecnologias leves e a falta de sistematização dos serviços intersetoriais.

A comunicação entre os profissionais foi compreendida também como um aspecto dorsal e desafiador no processo de trabalho em que estão inscritos, configurando um nó crítico explicitado na fala dos participantes: 
Muitas vezes acontecem muitas coisas aqui na UBS e a gente não fica sabendo [...] e aí a gente mesmo não sabe passar, porque falta a comunicação. (ACS2)

Eu pude perceber também, e que também nos falta, que precisa fortalecer, é a parte do diálogo, é a parte da comunicação, e a parte de espírito de equipe (GM1)

E eu acho que tendo um pilar, no caso a estratégia de comunicação, o resto vai fluindo tudo naturalmente. (ACE1)

Uma outra ótica da comunicação compreendida como necessária ao processo de trabalho é a que se relaciona à comunicação estabelecida com o usuário, que ainda constitui um nó a ser desatado pelos profissionais/gestores:

Precisamos divulgação do trabalho, para dar mais visibilidade do trabalho que a gente faz e conscientização da população em relação ao que é o nosso trabalho e o que não é nossa função. (ENF3)

A gente tem que ter o hábito de informar as pessoas, conhecer o serviço e saber informar. (GM1)

\section{Educação permanente}

O nó educação permanente surgiu a partir da observação do contexto e envolveu as práticas desenvolvidas, as habilidades técnicas, os processos formativos identificados dos profissionais e usuários e a compreensão da construção desse ambiente. Permitiu reconhecer a importância de um espaço formal e pactuado dentro do horário de serviço que possibilitasse aos sujeitos participantes repensarem, articularem e discutirem estratégias para a qualificação do processo de trabalho.

Como principais desafios tangíveis a este nó crítico destacam-se: a necessidade de problematizar e refletir as competências individuais e coletivas; a intencionalidade das ações desempenhadas; o exercício da educação continuada para o treinamento das habilidades técnicas a e efetividade do trabalho multiprofissional.

Em função da ausência de um horário protegido para a educação permanente e da participação nas oficinas - entendida como espaço para refletir o processo de trabalho -, os participantes perceberam o quanto a educação permanente carece ser realizada pelas equipes de saúde que atuam no cenário estudado. Salientam neste sentido que a educação permanente os auxiliaria a desenvolverem os seus papéis, ampliando o conhecimento necessário para atuarem no contexto do trabalho em saúde:

A capacitaçáo de fornecer e o conhecimento de a gente buscar, pois enquanto profissional, eu também tenho que buscar o conhecimento. (ENF1) 
Acho que tem que ter conhecimento, não adianta eu querer ser líder se eu não conheço. (BIO1)

Eu acho que a gente até poderia trabalhar essa educação permanente juntas nas duas equipes das ESF's [...]. Cada uma fala de um tema, aí outra enfermeira náo pararia o seu trabalho, eu não pararia o meu totalmente, e a nossa equipe estaria toda treinada. (ENF2)

Para a gente como técnico, essa participação da enfermeira com a gente, na capacitação vai mostrando novas coisas [...]. Então é uma parte que dá para interagir com todo mundo fazendo igual todos os dias. (TENF1)

\section{Planejamento}

O nó planejamento foi observado a partir dos elementos atrelados à observação das atividades desempenhadas, compreendendo se eram planejadas, executadas e avaliadas. A observação apontou uma complexidade de práticas sendo realizadas pelas diversas categorias profissionais que trabalhavam e se empenharam nas açóes executadas, porém muitas delas se perdiam sem registros e, consequentemente, sem reconhecimento e visibilidade.

O fluxo das ações precisava de sistematização. Cada profissional estabelecia sua rotina individual de trabalho e evidenciava-se uma lacuna ao observar a totalidade do processo de trabalho, dificultando a continuidade e a integralidade das açóes desempenhadas pelos membros da equipe.

O planejamento é também evidenciado pelos profissionais como um nó que dificulta a fluidez do processo de trabalho na APS. Neste sentido, entendem ser o planejamento uma ferramenta que pode diminuir a desarticulação e fragmentação do cuidado e da assistência à saúde:

A gente precisa bater muito na tecla de planejamento. Não é assim: "Eu quero, vamos fazer um negócio...”, não. Como que vai ser planejado amanhã? Nós vamos ter que aprender a planejar o dia a dia. (GM1)

Eu acho que fazendo o cronograma a gente força a seguir, e é muito bom. Porque se não tiver nada escrito... eu chego assim: "Deixa eu ver o que eu programei para eu fazer hoje". (ENF2)

Eu fazia um cronograma de todo o meu serviço: serviço de epidemiologia, vigilância em saúde, dos sistemas [...] e os dias que eu ia ficar com cada uma das meninas para ficar observando o trabalho delas. Eu já vou voltar com isso. (ENF1)

\section{Identidade}

O nó identidade descreve-se relacionado às características das açóes realizadas, considerando como premissa a identidade e o papel da APS, bem como o 
reconhecimento das competências profissionais neste cenário de atenção. A observação retratou a necessidade de os participantes serem estimulados a buscarem suas identidades profissionais e de compreenderem com maior definição suas competências, a fim de construírem uma identidade individual e de equipe que orientasse e ampliasse o sentido do cuidado.

No cotidiano observado, muitas demandas foram abordadas e conduzidas, estando ancoradas na cultura biomédica, o que diverge do modelo de atenção da APS. Evidenciou-se a necessidade de trabalhar o sentimento de pertença, de estimular a autonomia e a liderança, como também instigar a proatividade como força motora para transformação.

Como principais desafios deste nó, destacam-se: a falta de reconhecimento dos serviços; a falta de visibilidade profissional; a necessidade de desenvolvimento de visão da prática individual e coletiva, assim como a assistência com foco na integralidade.

No tocante ao nó identidade, os participantes apontam como imprescindível conhecer e identificar os seus papéis neste cenário, as competências dos colegas de equipe e o funcionamento do serviço como um todo:

$\mathrm{O}$ que eu pude perceber é que as próprias pessoas que trabalhavam às vezes não tinham essa identidade que a gente busca. Essa identidade... "eu sou ACS, mas o que é ACS?”; “eu sou enfermeiro, mas o que é enfermeiro?”; “eu sou do PSF mas não sei o que é PSF”; “eu sou administrativo mas o que eu faço?”.(GM1)

Eu acho que é importante cada funcionário saber sua função também. (TENF1)

A gente enquanto faxineira, a gente não sabe exatamente o que é da gente, o que é da técnica, né? (AL2)

A gente foi se comunicando entre nós e cada um foi se identificando, eu acho que falta essa oportunidade para cada um se identificar, por exemplo, eu sou do PSF, mas não sei o que é PSF. (GM1)

\section{Discussão}

A presente investigação traz à tona os nós críticos do processo de trabalho inscritos na prática cotidiana de profissionais/gestores que atuam no âmbito da APS, evidenciando que eles se tecem de forma dinâmica e transversal e se articulam de maneira indissociável e interdependente, exigindo uma permanente reconfiguração de suas práxis.

As “lentes” teóricas utilizadas para esta discussão foram as de Rudimar Baldissera (2009a) e Paulo Freire (1983; 1987), que descrevem a relação e a complementariedade 
entre comunicação e transformação, cada um por seu caminho e do seu modo. Sugere-se entâo o diálogo como ponto de encontro entre os dois referenciais, baseado na observação da realidade vivenciada pelos sujeitos e na experiência prática descrita pelos próprios profissionais.

Ao enfocar os nós críticos do processo de trabalho em saúde, toca-se em uma realidade necessária para a reorientação dos modelos assistenciais vigentes. A literatura afirma que essa reorientação somente será possível a partir da organização das práticas de saúde nos espaços da macro e micropolítica, lugares onde se inserem gestão, profissionais e usuários (GALAVOTE et al., 2016), os quais, de algum modo, estão representados na presente investigação.

Os discursos dos participantes e a observação do cenário estudado revelam a ambiência como um espaço físico que traz desafios para o processo de trabalho em saúde, impactando na sua dinâmica social, constituindo-se como um espaço de relaçóes e encontros. Tal concepção está em consonância com o conceito de ambiência estabelecido pela Política Nacional de Humanização (PNH), que compreende a ambiência como um espaço físico entendido como espaço social, profissional e de relações interpessoais, que deve prover uma assistência humana, acolhedora e resolutiva (BRASIL, 2010). Neste sentido, a ambiência vai além da composição técnica e formal dos espaços, pois se estabelece também através das situações e contextos construídos e vivenciados, devendo se firmar em três eixos: como um espaço de confortabilidade; como um espaço que possibilita encontros de sujeitos; e como um espaço facilitador do processo de trabalho (BRASIL, 2010).

Em relação à organização do espaço, evidencia-se que a ambiência exerce influência no processo de trabalho dos profissionais de saúde, tanto pela organização estrutural do espaço, quanto pelo aumento de profissionais e/ou disputa pelo espaço físico, gerando condiçôes inadequadas de trabalho. Tais condições inadequadas influenciam na organização do trabalho individual dos profissionais, na relação entre os profissionais e na organização do trabalho em equipe, bem como na relação profissional/usuário (GLANZN; OLSCHOWSKY, 2017). Segundo Baldissera (2009b), os sujeitos são mais do que resultado de uma cultura organizacional, pois existem variáveis ecossistêmicas - aqui compreendidas como espaço físico, social e relacional - que interagem como forças e admitem movimentos de resistência, potencialização, corporações, transformando os sentidos das práticas cotidianas, a realidade e o próprio sujeito. 
Paulo Freire (1987) postula que a transformação social deve se dar através dos seres humanos e do seu mundo, sendo ela necessária para a compreensáo do sujeito frente à sua realidade e às suas vivências. Complementa ainda que tal transformação fundamenta-se no pensamento-linguagem do sujeito, no seu nível de percepção da realidade, na sua visão de mundo e nas relações estabelecidas em seu contexto (FREIRE, 1987).

No que tange à comunicação, evidencia-se que ela traduz um importante nó crítico inscrito no processo de trabalho em saúde, sendo explicitado nos relatos dos participantes e também na observação realizada. Segundo Rudimar, os ambientes organizacionais são atravessados pela comunicação, por meio da qual o organizado convive com o desorganizado, o consciente com o inconsciente e assim se constrói a identidade organizacional através do repensar desse processo comunicativo estabelecido (BALDISSERA, 2009a; 2009b).

A comunicação interprofissional, caracterizada pelo envolvimento de diferentes setores e práticas profissionais contribui para melhores resultados de saúde e satisfação dos profissionais, sendo capaz de garantir a integralidade das açôes de cuidado e transformar a realidade do serviço (PREVIATO; BALDISSERA, 2018), constituindo-se como elemento-chave no trabalho em equipe. No entanto, para que o processo comunicativo se efetive, é necessário que toda a equipe esteja empenhada em prol desse objetivo, buscando manter um diálogo claro e transparente. Neste sentido, Baldissera (2009b) afirma que os ambientes organizacionais são de forma transversal constituídos por capilares de comunicação que, em algum momento, têm o potencial de forçar as ordens impostas, em busca de reconhecimento e de uma nova organização.

Além da comunicação entre os profissionais de saúde, destaca-se também a comunicação com o usuário, que é igualmente essencial para que o cuidado seja ofertado e recebido de forma eficiente. A ausência de uma comunicação bem estabelecida entre os participantes impacta diretamente na fragmentação do cuidado. Isso é percebido no estudo como gerador de um processo de trabalho conflituoso, com limitaçóes relacionadas, inclusive, ao acesso do usuário no serviço de saúde.

Estudo realizado com 30 usuários entre 18 e 80 anos atendidos em uma unidade de saúde de uma regiáo do interior de Portugal revelou, nos discursos dos participantes, que a comunicação deficiente entre os profissionais de saúde dificultou o trabalho em equipe e consequentemente a assistência prestada aos usuários (NUNES, 2019). 
Isso evidencia que o usuário percebe a qualidade do serviço de saúde através de elementos além da clínica, como por exemplo os processos relacionais e vínculos estabelecidos entre usuário/profissionais (ARRUDA; BOSI, 2017).

Evidenciado por Morais e colaboradores (2020), a falta de comunicação entre população e serviços de saúde impacta a APS, resultando no desconhecimento dos usuários acerca de quais os serviços disponíveis, fragilizando o atributo de primeiro contato e o reconhecimento desse nível de atenção como porta de entrada do SUS.

Pensar a reorganização do processo de trabalho remete adentrar na proposta da Educação Permanente em Saúde (EPS), figurada neste estudo como um nó crítico, com a finalidade de (trans)formar as práticas profissionais no cotidiano dos serviços, visando atender às reais necessidades da população (SILVA; MATOS; FRANÇA, 2017).

A EPS surge, portanto, como esses conhecimentos, habilidades e o enfrentamento dos desafios postos no cotidiano da produção do cuidado em saúde (BOMFIM et al., 2017). Permite, desse modo, a reorganização de estratégias de intervenção educativa aplicadas ao trabalho, possibilitando transformar relaçóes e a articulação dos serviços entre profissionais, gestáo e usuários. Pauta-se na problematização do trabalho vivo em ato, corroborando para a atualização contínua das práticas através do reconhecimento dos nós críticos existentes nas mesmas e do exercício da tríade ação-reflexão-ação (MACHADO et al., 2015).

A compreensão da realidade é essencial para o desenvolvimento do conhecimento libertador, através da captação das complexidades, da dinâmica e das relaçôes estabelecidas. Neste sentido, o que se pode fazer como contribuição nesse processo é potencializar as vozes que já existem nos sujeitos, estimulando, através do diálogo, indivíduos mais ativos no seu mundo capazes de conduzir, por meio da vivência e da reflexão, o processo de transformação da realidade (FREIRE, 1983; 1987). O legado de Paulo Freire vai, portanto, ao encontro do que se constitui a educação permanente, que se pauta na construção de espaços coletivos de reflexão sobre o cotidiano do trabalho e no estímulo à aprendizagem significativa, ao engajamento político e ao movimento de mudança da realidade.

Ainda no tocante aos nós críticos emergidos, destaca-se o planejamento. A ausência de uma sistematização das açôes e serviços, associada a uma rotina individualizada de atuação dos profissionais apresentaram-se neste contexto como questôes dorsais. No cenário estudado, a necessidade de planejamento surge como uma possibilidade 
de ordenar e delinear melhor o cuidado ofertado e de organizar a equipe, com uma atuaçáo articulada, interprofissional e com enfoque na integralidade. $\mathrm{O}$ planejamento é um instrumento de gestão fundamental e deve ser considerado sob a lógica permanente, coletiva e participativa, pois permite o alcance de objetivos e define caminhos para a melhoria e a qualificação dos serviços ofertados à população, rompendo com a lógica fragmentada e desarticulada entre os diversos atores e serviços envolvidos no processo de trabalho (FIGUEIREDO et al., 2020).

Estudo realizado com profissionais que atuam na APS evidenciou que, entre os fatores que interferem na organizaçáo do processo de trabalho, destacam-se a falta de um processo de educação permanente, a não realização do planejamento coordenado, a falta de monitoramento e avaliação das ações, a fragmentação da rede de atenção à saúde e a burocratização das relaçóes intersetoriais (VECCHI; CAMPOS; FARAH, 2017), estando tais achados consoantes com os resultados da presente investigação.

A identidade profissional, circunstanciada à identidade do cenário em que atuam, também figurou como um nó crítico observado e reafirmado por esta pesquisa. A dificuldade no reconhecimento e definição de papéis de cada profissional constitui um desafio inscrito no processo de trabalho. Os discursos do gestor municipal e de profissionais das equipes de saúde denotam o quanto muitas vezes não fica claro para aquele e para estes a competência de cada profissão, sendo isso uma lacuna que se origina na matriz identitária de cada profissional e da equipe.

A identidade profissional é observada e retratada pelos profissionais como necessária para a reorganização do trabalho em saúde. Sabe-se que a construção da identidade profissional não é dissociada das condiçôes e da configuração do local de trabalho e da própria formação profissional. Segundo Rudimar Baldissera (2009b), a identidade organizacional é formada pelo que ela se mostra intencionalmente para as pessoas e pelo que não é intencional. Dessa maneira, ela é construída por um processo de dialogicidade que pressupóe autonomia e pensamento crítico. Paulo Freire defende, ainda, o quanto a construção de identidade torna o sujeito legitimado e liberto através da autonomia, sendo assim capaz de gerar transformação da sua realidade social (FREIRE, 1987).

O estudo limitou-se a um recorte específico do cenário pesquisado, evidenciando assim os desafios do processo de trabalho inscritos em um contexto singular. Em outras realidades, com atores e vivências distintos, outros nós críticos podem 
estar presentes, os quais merecem ser estudados e problematizados por outros pesquisadores, ampliando as evidências científicas tangíveis ao objeto ora desvelado.

\section{Considerações finais}

A presente investigação possibilitou a identificação de nós críticos inscritos no processo de trabalho da APS a partir da observação/análise dos pesquisadores e da validação desses nós pelos atores sociais envolvidos. Ressaltou a importância de alguns aspectos entremeados e muitas vezes não visibilizados no cotidiano do trabalho, os quais geram "perturbaçóes" cotidianas que desafiam os profissionais na produção do cuidado em saúde. Assim, pode-se considerar que a ambiência, a identidade profissional, a comunicação, o planejamento e a educação permanente expressaram categorias temáticas e produtoras de uma comunicação dialógica entre pesquisadores e os participantes, potencializando a perspectiva teórica dos referenciais adotados neste estudo.

De posse desse processo de comunicação provocado pela pesquisa-ação, apontam-se desdobramentos imediatos em alguns nós críticos que, após refletidos pelos participantes, estes se viram estimulados a desatá-los. Como exemplo, destacase a reorganização do espaço e a separação das recepçóes do PA e ESF, refletindo diretamente no melhor delineamento dos fluxos assistenciais, na comunicação entre os profissionais e no direcionamento dos usuários. Compreende-se então a importância da pesquisa-ação no processo de afetar e provocar transformaçôes no contexto social, por meio da participaçáo ativa e da autonomia dos sujeitos que compõem a realidade pesquisada.

Os resultados sugerem a importância de os profissionais/gestores refletirem sobre seus processos de trabalho, potencializando espaços de educaçáo permanente que pautem o ambiente físico, estrutural e social do trabalho, a importância de ferramentas de planejamento e gestão do mesmo, a identidade e os papéis reais e ideais do serviço e dos profissionais da APS e, sobretudo, a comunicação como eixo transversal do trabalho em saúde.

Este movimento, sendo contínuo e intencionalmente voltado para a reorganização do trabalho em saúde, figura como indutor na incorporação dos princípios do SUS no cotidiano da APS e na reorientaçáo do modelo assistencial. Espera-se que o enfrentamento aos desafios impostos à micropolítica do trabalho em saúde - 
pautados nesta investigação - seja uma militância assumida no ensino, na pesquisa e no serviço pelos que acreditam no fortalecimento do SUS. ${ }^{1}$

\section{Referências}

ARRUDA, C. A. M.; BOSI, M. L. M. Satisfação de usuários da atenção primária à saúde: um estudo qualitativo no Nordeste do Brasil. Interface (Botucatu), v. 21, n. 61, p. 321-332, 2017.

BALDISSERA, R. A comunicação no (re)tecer da cultura organizacional. Revista Latinoamericana de Ciencias de la Comunicación, São Paulo, v. 10, n. 6, p. 52-62, 2009 b.

. Comunicação Organizacional na perspectiva da complexidade. Organicom, São Paulo, v. 6, n. 10-11, p. 116-120, 2009a.

BARDIN, L. Análise de conteúdo. Lisboa: Ediçōes 70, 2016.

BOMFIM, E. S. et al. Educação permanente no cotidiano das equipes de saúde da família: utopia, intenção ou realidade? Revista de Pesquisa: Cuidado é Fundamental Online, [S.1.], v. 9, n. 2, p. 526-535, 2017.

BRASIL. Ministério da Saúde. Secretaria de Atenção à Saúde. Núcleo Técnico da Política Nacional de Humanização. Ambiência. 2. ed. Brasília: Editora do Ministério da Saúde, 2010. 32 p.

FERREIRA, L. et al. Educação Permanente em Saúde na atenção primária: uma revisão integrativa da literatura. Saúde debate, Rio de Janeiro, v. 43, n. 120, p. 223-239, 2019.

FIGUEIREDO, I. D. L. et al. Planejamento estratégico como ferramenta de gestão local na atenção primária à saúde. REFACS, Uberaba, v. 8, n. 1, p. 27-38, 2020.

FREIRE, P. Extensão ou comunicaçâo? 7. ed. Rio de Janeiro: Paz e Terra, 1983.

. Pedagogia do oprimido. 17. ed. Rio de Janeiro: Paz e Terra, 1987.

GALAVOTE, H. S. et al. A gestão do trabalho na estratégia saúde da família: (des)potencialidades no cotidiano do trabalho em saúde. Saúde Soc., São Paulo, v. 25, n. 4, p. 988-1002, 2016.

GLANZN, C. H.; OLSCHOWSKY, A. A ambiência e sua influência no trabalho de equipes de saúde da família. Revista Saúde e Desenvolvimento Humano, Canoas, v. 5, n. 1, p. 7-14, 2017.

INSTITUTO BRASILEIRO DE GEOGRAFIA E ESTATÍSTICA. Cidades e Estados. Rio de Janeiro, 2010. Disponível em: https://www.ibge.gov.br/cidades-e-estados/mg/cajuri.html. Acesso em: 3 nov. 2019.

. Portal Cidades. Rio de Janeiro, 2019. Disponível em: https://cidades.ibge.gov.br/ brasil/mg/cajuri/panorama. Acesso em: 3 nov. 2019.

MACHADO, J. F. F. P. et al. Educação Permanente no cotidiano da Atenção Básica no Mato Grosso do Sul. Revista Saúde Debate, Rio de Janeiro, v. 39, n. 104, p. 102-113, 2015. 
MENEZES, E. L. C. et al. Modos de produção do cuidado e a universalidade do acesso análise de orientaçóes federais para o trabalho das equipes da APS no Brasil. Ciênc. saúde colet., Rio de Janeiro, n. 25, v. 5, p. 1751-1763, 2020.

MENDES-GONÇALVES, R. B. Prática de saúde: processos de trabalho e necessidades. In: AYRES, J.R.; SANTOS, L. (Org.). Saúde, Sociedade e História. 1. ed. São Paulo: Hucitec/ Porto Alegre: Rede Unida, 2017. p. 294-374.

Tecnologia e organização social das práticas de saúde: características tecnológicas do processo de trabalho da rede estadual de Centros de Saúde de São Paulo. 1986. Tese (Doutorado em Medicina Preventiva) - Faculdade de Medicina, Universidade Federal de São Paulo, São Paulo, 1986.

MERHY, E. E. Em busca do tempo perdido: a micropolítica do trabalho vivo em saúde. In: . (Org.). Agir em saúde: um desafio para o público. Sáo Paulo: Editora Hucitec/ Buenos Aires: Lugar Editorial, 1997. p. 74-111.

MORAIS, I. C. O. et al. A percepção do usuário em relação à qualidade do atendimento na atenção primária à saúde. Revista Eletrônica Acervo Saúde, [S.I.], n. 50, p. e3465, 2020.

MORIN, A. Pesquisa-ação integral e sistêmica: uma antropopedagogia renovada. Rio de Janeiro: DP\&A, 2004.

NUNES, A. M. A importância da comunicação com profissionais de saúde: o olhar dos usuários na atenção primária à saúde no interior de Portugal. Saúde em Redes, [S.1.], v. 5, n. 2, p. 113-121, 2019.

PREVIATO, G. F.; BALDISSERA, V. D. A. A comunicação na perspectiva dialógica da prática interprofissional colaborativa em saúde na Atenção Primária à Saúde. Interface (Botucatu), v. 22, supl. 2, p. 1535-1547, 2018.

SILVA, K. L.; MATOS, J. A. V.; FRANÇA, B. D. A construção da educação permanente no processo de trabalho em saúde no estado de Minas Gerais, Brasil. Esc. Anna Nery, Rio de Janeiro, v. 21, n. 4, e20170060, 2017.

THIOLlENT, M. Metodologia da pesquisa-ação. 18. ed. São Paulo: Cortez, 2011.

VECCHI, M. P. S.; CAMPOS, E. M. S.; FARAH, B. F. Autoavaliação: instrumento para reflexão do processo de trabalho nas equipes de saúde da família. Rev. APS, Juiz de Fora, v. 20, n. 4, p. 527-538, 2017.

\section{Nota}

${ }^{1}$ V. S. Amaral: pesquisa de campo, coleta de dados, análise e interpretação dos dados e redação do texto. D. S. Oliveira: análise e interpretação dos dados, redaçấo e revisão do texto e orientou o estudo. C.V. M. Azevedo: análise e interpretação dos dados e redação do texto. R. L. M. Mafra: análise e interpretação dos dados, revisão do texto e co-orientou o estudo. Este trabalho é parte da produção acadêmica de uma dissertação de mestrado profissional em Ciências da Saúde, na linha de pesquisa de Saúde Pública e Cuidados em Saúde - Departamento de Medicina e Enfermagem - Universidade Federal Viçosa. Financiamento: CNPq. 


\section{Abstract}

The critical nodes of the work process in Primary Health Care: an action research

Qualitative research with an action research approach whose objective was to identify the critical nodes enrolled in the Primary Health Care (PHC) work process. Forty-four PHC professionals / managers from a municipality in the interior of Minas Gerais participated. Data collection took place from June to December 2019, using the participant observation technique and later through workshops with the participants. The data were analyzed using Bardin's Content Analysis technique and from the perspective of the theoretical frameworks of Rudimar Baldissera and Paulo Freire. The analysis allowed the emergence of five categories, which expressed the critical nodes identified in the participant observation and validated by the professionals in the workshops: ambience, communication, continuing education, planning and professional identity. This research signals the importance of dialogue as an instrument of transformation within the health work process.

> Keywords: Primary Health Care; interdisciplinary health team; work; change management; institutional development. 